\title{
Utilization of the mental health services among the Yemeni peoples, IBB city, Yemen
}

\author{
SalahGhalib AhmedMojali ${ }^{1}$, Bader F.Al-shabrain ${ }^{2}$ \\ ${ }^{1,2}$ Department of Health Administration College of Business Administration King Saud University, Riyadh, \\ Kingdom of Saudi Arabia
}

\begin{abstract}
:
Background:The specific objectives addressed in this paper are to assess the utilization of mental health. In particular identify barriers which prevent uses of these services, suggestions for encourageuses of the services at IBB city in Yemen. Method the data were drawn by using the questionnaire, a sample random sampling procedures to select 493 peoples at IBB city randomly, using a descriptive analysis Results the researchers found that $42.8 \%$ of the participants use the informal types of services (spirits, herbs), $20.3 \%$ of participants use the formal services(psychiatrics)while $36.9 \%$ didn't use both. $71.6 \%$ of participants need to use the mental health services but they didn't use.Most common barriers prevent using were Preference informal help(friends)represent 19.3\%, Difficulty of access for mental health services represent 13.5\%.the most common gap was mental health services are not available represent $1.5 \% .85 .8 \%$ of the participants were unsatisfied. they suggested the following : the cost of treatment must be an appropriate, the mental health centers should be close to the community, availability of mental health specialists, Raise the level of awareness in the community about mental health.
\end{abstract}

Conclusion:these finding are the first to document barriers prevent the peoples from use the mental health services although they need to use.

Key Words:Barriers in services, formal, mental, utilization ofhealth services.

\section{Introduction}

Psychiatric disorders are among the top causes worldwide of disease burden and disability both for the individuals suffering from them and their families.(Baca,2007).By 2020, it is projected that the burden of psychiatric disorders will have increased to $15 \%$ of the total Disability Adjusted Life Years lost due to all diseasesandinjuriesPsychiatric patients have longer lengths of hospital stay than other patient in the other departments.Many studies have been carried out that aimed toGain understanding about the predictors and determinants of health service uses.Certain variables like male sex, younger age, being unmarried, unemployed, other psychotic disorders, personality disorders, and substance use disorders have traditionally been related to mental health service use. there are two types of disorders:anxiety disorders (generalized anxiety disorder, panic disorder, simple phobia, social phobia, obsessive compulsive disorder, separation anxiety disorder)(sagman ,2009)andmood disorders (major depression, dysthymia, substance use disorders, eating disorders).There are two types of the services either formal services(psychiatrist) or informal use(Spiritual doctor, doctor of herbs).(khouzam,2005).

But in the other hand there is a many people suffers from problems either simple like stress or difficult like depression, but they couldn't go to the mental Health services, or use the informal servicesThere are many of causes which prevent persons from go to the mental health services.

The lack of knowledge about the utilization of mental health services is clearly observed at IBB city in Yemen. The researcher will investigate this issue :by evaluation the types of services, evaluation the assessment feeling the need to use services, the barriers or causes which prevent the persons from conduct these services and evaluation the satisfaction, suggestions for encourage the uses of the mental health services.

This is a new study on our society has not been studied this subject before. Lack of the knowledge about the users and the barriers prevent the using of the mental health services at IBB city in Yemen.

On the basis of this, the current study attempts to answer the following questions:

1- Are there people use informal mental health services?( assess the utilization of mental health services either formal or informal or not use neither).

2-Do the people feel the need to use mental health services but there are barriers prevent them from use? what are the main barriers which prevent some peoples who need the consultation from use the services?

3-Are the people satisfied about the current mental health services, what are the suggestions for encourage the use of mental services? 
This study will be confine the peoples at Al-Dehar area, IBB city in Yemen.this study will be done from1/4/2013 to 30/8/2013.this study will assessment the users of the mental health services either formal or informal, identify the barriers that prevent uses of the a mental health services and evaluate the suggestions for encourage the uses.

\section{Variables definition:}

Users of the mental health services: any one seek the mental services. Above the age 18year

Formal and unformal services: formal mean seek the services from the psychiatrics, informal mean seek the services from the spirits or herbs.gaps (non-existent services) and barriers (problems that prevent access to existingservices). 9

\section{Background}

Numerous studies have documented the significant association between personality factors and the use of mental health services among adults in the general population.LikeGoodwin(2002)show the significantassociation between personality factors andthe use of mental health services among adults in thegeneral population, in which the Neuroticism $[\mathrm{OR}=1.5(1.2,1.9)]$ was associated with significantly increased likelihood of mental health service utilization among adultsin the community.

Alonso In( 2000) and Tamsin in( 2010) did research (Use of mental health services in Europe: The results suggest that the use of mental health services is limited among individuals with mental disorders(mostly mood disorders) in the European countries studied. The factors associated with this limited access and their implications deserve further research.Ting in (2006) done research(depressive symptoms in a simple of social worker students and reasons preventive student from using mental health services)which aim to examine the level of depressive symptoms and explore the causes which result in that the fear from the psychiatrist and loss the time.Enrique in (2007) done(Patterns of mental health service utilization in a general hospital and outpatient mental health facilities)He result in that the Mental healthcare costs were not evenly distributed throughout the patient population.

Brandon in (2012) done research(Factors Affecting Mental Health Service Utilization Among Deployed Military Personnel)Researcher result in Deployed service members may face similar or increased barriers to mental health services as compared to non-deployed members.Yoon in( 2013) done (The Role of Adverse Physical Health Events on the Utilization of Mental Health Services.the researcher result in that theMental health services uses increases with the severity ofa physical health condition.

Quartana(2014) result in that there were increased in mental health services utilization and decreased stigma in US soldiers between 2002 and 2011. These trends were evident in soldiers with and without posttraumatic stress disorder (PTSD), major depressive disorder (MDD ), or PTSD and MDD. Despite the improving trends, more than half of soldiers with mental health problems did not report seeking care.Tsai(2014) result in that there was no differences between Asian American and Pacific Islander in health service use or perceived barriers or stigma related to mental health services. Davis(2014)Study indicate that there was no ethnic or gender differences in the use of specialty mental health services or in the use of mental health treatmentsMaclean(2014) study the associations between A2 disorders and high-cost health care utilization in a large, nationally representative survey. The findings underscore the potential implications of these disorders on health care expenditures. Fleury(2014) 46.5\%) reported having used healthcare services for MHR. Determinants of service utilization were emotional and legal problems. Cairney(2014) identify 1213 individuals with past-year disorder. In the year after the survey, $24 \%(\mathrm{n}=312)$ of these had a mental health-related physician consultation. Logistic regression revealed that age, sex and marital status predicted service use.Ziller(2010) Study findings show a complicated pattern of greater need among rural than urban adults for mental health services, lower rural office-based mental health use and higher rural prescription use, and no rural-urban differences in total or outof-pocket expenditures for mental health services.Yoon(2013) result in that the adverse physical health event substantially increases the utilization of mental health care. Mental health service use increases with the severity of a physical health condition.Gould (2012)study the barriers and the gabs which prevent the using of the mental health services, the researcher result in that the gap most frequently recognized was lack of providers (74\%), while lack of funding $(52 \%)$ was the most common barrier.

The previous studies were either for specific group or evaluate the mental health in general or assess the problems associated with use of the service, but the researcher in this study will assess andidentify the prevalence of people who use the formal and informal mental health services, also identify the prevalence rate of peoples who need to use the services but there are a barriers prevent themfromusing the services, the researcher need to detect the causes,. and evaluate satisfaction of peoples regarding the current mental services and there suggestions for encourage peoples to use the mental health services. 
Population and Sampling:

\section{Methods}

\section{Populations:}

The study population consisted from all peoples at AL-Dehar area at IBB city in Yemen.

Sampling procedure:

The sample will cover 493 peoples ,by using simple random sampling, peoples derived from AlDeharareaat IBB city in Yemen.

\section{Measures}

Questionnaire

The survey instrument used in this study is a questionnaire which was developed by the researcher. It also consists of 5 questions, (yes, no questions)

Except questions 2 and 5 are multiple selections.

questionnaire made up from 2 different sections as follows:

- Section 1 asks about: socio-demographic information.

- Section 2 asks for information regarding the using of mental health services.(type of user, barrier, satisfaction, suggestions for encourage the users).

Questionnaire validityand reliability: To assure the validity, the following procedures were conducted. Firstly, review was made of the relevant literature and the previous instruments were examined to develop drafts. Secondly, the questionnaire was given to professors of health care administration to judge it. Reliability was measured by using Cronbachalpha tool.

Reliability Statistics
\begin{tabular}{|l|l|}
\hline Cronbach's Alpha & N of Items \\
\hline .85 & $\mathbf{1 6}$ \\
\hline
\end{tabular}

\section{Research design:}

The current study follows a survey-study approach and method design. It attempted reaching a certain description for the level of the problems which can be explored and investigated further using another and/or other research designs.

\section{Procedure}

The researcher gathered data by his friends, while the assistants explained the tools used in the study prior to collecting sample data though questionnaires. after that distributed all desirable questionnaires directly to all participantsin the area .The data collection from 1/4/2013 to 30/8/.An average 4 minutes was required to complete the instrument. nearly 550 copy of questionnaire distributed 45 questionnaire form didn't return. From505 form there are 12uncompleted (misused items)the response rate was $89.9 \%$.A total of 493 of 550 (84.9\%) questionnaire forms were returned.

\section{Results}

The data was analyzed using SPSS version19, descriptive study.This study aimed at investigating the barriers prevent use of the mental health services at IBB city, Yemen. The raised questions in this study were: 1- Are there people use informal mental health services?( assess the utilization of mental health services either formal or informal or not use neither).

2- Do the people feel the need to use mental health services but there are barriers prevent them from use?what are the main barriers which prevent some peoples who need the consultation from use the services?

3 -Are the people satisfied about the current mental health services, what are the suggestions for encourage the use of mental services?

Tables(1) show socio-demographic characteristics of respondent

\begin{tabular}{|c|c|c|c|}
\hline & Variables level & Frequency & $\%$ \\
\hline \multirow{3}{*}{ Gender } & Male & 276 & 56.0 \\
\hline & Female & 217 & 44.0 \\
\hline & Total & 493 & 100.0 \\
\hline \multirow{5}{*}{ Age } & $18-24 y$ & 156 & 31.6 \\
\hline & $25-29 y$ & 85 & 17.2 \\
\hline & $30-39 y$ & 114 & 23.1 \\
\hline & 40 above & 138 & 28.0 \\
\hline & Total & 493 & 100.0 \\
\hline
\end{tabular}


Utilization of the mental health services among the Yemeni peoples, IBB city, Yemen

\begin{tabular}{|c|c|c|c|}
\hline \multirow{3}{*}{ Marital status } & Married & 251 & 50.9 \\
\hline & Unmarried & 242 & 49.1 \\
\hline & Total & 493 & 100.0 \\
\hline \multirow[t]{3}{*}{ Employment status } & Employed & 232 & 47.1 \\
\hline & Unemployed & 261 & 52.9 \\
\hline & Total & 493 & 100.0 \\
\hline \multirow[t]{3}{*}{ Level of education } & UNDER HIGH SCHOOL & 99 & 20.1 \\
\hline & HIGH SCHOOL , ABOVE & 394 & 79.9 \\
\hline & Total & 493 & 100.0 \\
\hline
\end{tabular}

It can be clearly seen that most of the participants were from male represent $56 \%$ then female with $44 \%$.In regard to age of the participants, most of the participants ages range from age 18-24 years representing $31.6 \%$,followed by $30-39$ years representing $23.1 \%$ and then 40 years and above representing $28 \%$. The last age range was 25-29 years representing only $17.2 \%$.it can be noticed that most of the participants were married represent $50.9 \%$,then unmarried represent $49.1 \%$.it can also be noticed that the most of participants were unemployed represent $52.9 \%$,then employed $47.1 \%$.most of the participants qualification were high school and above represent $79.9 \%$.then under the high school represent $20.1 \%$.

Tables(2)What are the kind of mental health services used by?

\begin{tabular}{|r|r|r|r|r|}
\hline What kind of mental health services used by? & Frequency & Percent & Valid Percent & Cumulative Percent \\
\hline Not use & 182 & 36.9 & 36.9 & 36.9 \\
Use formal & 100 & 20.3 & 20.3 & 57.2 \\
Use informal & 211 & 42.8 & 42.8 & 100.0 \\
Total & 493 & 100.0 & 100.0 & \\
\hline
\end{tabular}

$42.8 \%$ use the informal types of services (spirits, herbs), $20.3 \%$ use the formal services(psychiatrics) while $36.9 \%$ didn't use both.

Tables(3)Do you feel the need to use mental health services, but you didn't?

\begin{tabular}{|r|r|r|r|r|}
\hline Do you feel the need to use mental health services? & Frequency & Percent & Valid Percent & Cumulative Percent \\
\hline Yes & 353 & 71.6 & 71.6 & 71.6 \\
No & 140 & 28.4 & 28.4 & 100.0 \\
Total & 493 & 100.0 & 100.0 & \\
\hline
\end{tabular}

Most of participants need to use the mental health services but they didn't use represent $71.6 \%$, while $28.4 \%$ didn't feel need to use the mental health services.

Tables(4)What are the barriers and gap which prevent the persons from using mental services? in sequence according to the prevalence rate.

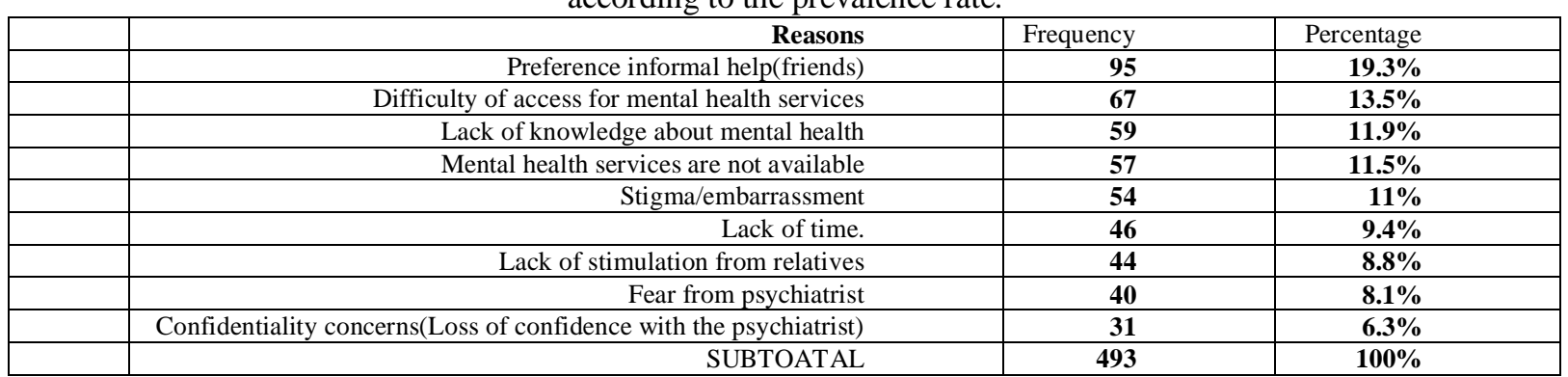

Most common causes or barriers prevent using the mental health services were Preference informal help(friends)represent $19.3 \%$, followed by Difficulty of access for mental health services represent $13.5 \%$, then Lack of knowledge about mental health represent $11.9 \%$, then Mental health services are not available represent $11.5 \%$, then Stigma/embarrassment represent $11 \%$,then Lack of time represent $9.4 \%$,then Lack of stimulation from relativesrepresent $8.8 \%$, then Fear from psychiatrist represent $8.1 \%$ and Confidentiality concerns(Loss of confidence with the psychiatrist)represent $6.3 \%$.

Tables(5) Are you satisfied with the health services provided in health centers?

\begin{tabular}{|cl|l|l|l|l|}
\hline Satisfaction & Frequency & Percent & Valid Percent & Cumulative Percent \\
\hline Satisfied & 71 & 14.4 & 14.4 & 14.4 \\
unsatisfied & 422 & 85.6 & 85.6 & 100.0 \\
Total & 493 & 100.0 & 100.0 & \\
\hline
\end{tabular}

Most of the participants were unsatisfied represent $85.8 \%$, while $14.2 \%$ were satisfied 
Tables(6) :Suggestions for encourage the mental health services uses:

\begin{tabular}{|l|r|r|}
\hline \multicolumn{1}{|l|}{ Suggestions for encourage the use } & Frequency \\
\hline 1-That the cost of treatment must be an appropriate. & 161 \\
& Percent \\
& 4-Mental health centers should be close to the community. & 32.7 \\
& 3 -Availability of mental health specialists. & 155 \\
31.5 & 95 \\
19.3 & 82 \\
16.5 & 493 \\
\end{tabular}

The participants suggest the following for encourage the use of the mental health services $32.7 \%$ suggest that that the cost of treatment must be an appropriate, $31.5 \%$ suggest that the mental health centers should be close to the community, while $19.3 \%$ suggest availability of mental health specialists, $16.5 \%$ suggest that the Raise the level of awareness in the community about mental health is important.

\section{Discussion}

The results of this study came in agreement to our initial expectations.42.8\% of the participants use the informal types of services (spirits, herbs), 20.3\% of participants use the formal services(psychiatrics) while $36.9 \%$ didn't use both. $71.6 \%$ of participants need to use the mental health services but they didn't use, This mean that the people still until now believe on the spirits and herbs. which interpret the lower visit mental health services.

Many articles have described the utilization of the mental health services and the pattern of use mental health services like Alonso (2000) and Thomas (2010) which result in that the uses of the mental services is limited among individuals with the mental disorders. Butnone have carefully examine the types of the services either formal or informal, also why there are a people need the mental health services either consult or treatment but they couldn't consult, what are the causes behind this problems .

The study of Alonso (2000) and Thomas (2010) supported our study that the any one with mental health disorders will use the metal health services,alsoFleury(2014) 46.5\%) reported having used healthcare services for MHR. Determinants of service utilization were emotional and legal problems.but our study will identified the causes which prevent the persons who need the services from go to the services.

Most common causes or barriers prevent using the mental health services were Preference informal help(friends)represent $19.3 \%$, Difficulty of access for mental health services represent $13.5 \%$, Lack of knowledge about mental health represent $11.9 \%$, Mental health services are not available represent $11.5 \%$, Stigma/embarrassment represent $11 \%$, Lack of time represent $9.4 \%$, Lack of stimulation from relatives represent $8.8 \%$,Fear from psychiatrist represent $8.1 \%$ and Confidentiality concerns(Loss of confidence with the psychiatrist)represent $6.3 \%$.the result of this study differ from the results of the

Gould (2012)study the barriers and the gabs which prevent the using of the mental health services, the researcher result in that the gap most frequently recognized was lack of providers (74\%), while lack of funding (52\%) was the most common barrier. The participants prefer use the informal helps like friends was interpret the high percentage of the informal use of the mental health services(spirits and herbs).

All of these causes indicate that there are many of the people suffer from the mental illness(simple, mild, or severe) but they didn't use, which required urgent intervention from the health authority.

85.8\% reported Dissatisfied about the mental health services, due to difficult for getting the services and others due to duplication of the informal services. they reported suggestions for encourage the uses of mental health services like:32.7\% suggest that that the cost of treatment must be an appropriatewhich support Briton(2012) and Baca (2007) using the active databases to study the cost of the mental health services and the causes which limit the access to the mental health services, $31.5 \%$ suggest that the mental health centers should be close to the community, while $19.3 \%$ suggest availability of mental health specialists, $16.5 \%$ suggest that the Raise the level of awareness in the community about mental health is importantavailability of mental health specialists $19.3 \%$ and Raise the level of awareness in the community about mental health $16.5 \%$.

\section{Conclusion}

Since the general aim of the study is to evaluate the utilization of the mental health services ,the study show that there were persons feel the need to use the services but there are a barriers prevent them for uses, also show the high percentage $85.6 \%$ un satisfied about the mental health services. also there were a suggestion for improve the mental health services also encourage the uses of services like mental health centers should be close to the community, the cost of treatment must be an appropriate availability of mental health specialists and Raise the level of awareness in the community about mental health. 


\section{Recommendations}

- There must be emphasized on the role of patient education program about the formal mental health services. also reduce the informal mental health services.

- Decision-makers in the health office must Encourage the uses of the services by the following suggestions:

Mental health centers must be close to the community, availability of mental health specialists and Raise the level of awareness in the community about mental health.

- Psychiatrist Must deal with the patient that he is not patient and give him the confidence and removes him from fear.

- Mental health services must be available in all primary health care centers.

- The cost of the treatment must be an appropriate.

\section{Limitation}

- This study conducted in Al-Dehar area, Other study should be conducted in other areas at IBB city.

- Another Limitation is related to methodology used in this study, the questionnaire used is not the best data collection tool. future study must use the interview to gather more data from peoples.

- Time is limited to conducting such type of study.

- Despite the efforts to evaluate themental health services ,the researcher facing challenges in which some peoples refuse the participants due to social stigma form any subject related to the Mental Health.

- These study confine to the mental health evaluation in the urban area, future study must be evaluate the people in rural areas.

\section{References:}

[1]. Quartana, P. J., Wilk, J. E., Thomas, J. L., Bray, R. M., Rae Olmsted, K. L., Brown, J. M., \& ... Hoge, C. W. (2014). Trends in Mental Health Services Utilization and Stigma in US Soldiers From 2002 to 2011. American Journal Of Public Health, 104(9), 1671-1679. doi:10.2105/AJPH.2014.301971

[2]. Tsai, J., Whealin, J. M., \&Pietrzak, R. H. (2014). Asian American and Pacific Islander military veterans in the United States: health service use and perceived barriers to mental health services. American Journal Of Public Health, 104 Suppl 4S538-S547. doi:10.2105/AJPH.2014.302124

[3]. Davis T, Deen T, Fortney J, Sullivan G, Hudson T. Utilization of VA Mental Health and Primary Care Services Among Iraq and Afghanistan Veterans With Depression: The Influence of Gender and Ethnicity Status. Military Medicine [serial online]. May 2014;179(5):515-520. Available from: Academic Search Complete, Ipswich, MA. Accessed November 8, 2014.

[4]. Maclean, J. C., Xu, H., French, M. T., \&Ettner, S. L. (2014). Mental health and high-cost health care utilization: new evidence from Axis II disorders. Health Services Research, 49(2), 683-704. doi:10.1111/1475-6773.12107

[5]. Fleury, M., Grenier, G., Bamvita, J., \& Caron, J. (2014). Determinants and patterns of service utilization and recourse to professionals for mental health reasons. BMC Health Services Research, 14(1), 1-23. doi:10.1186/1472-6963-14-161

[6]. Cairney, J., Veldhuizen, S., Vigod, S., Streiner, D. L., Wade, T. J., \&Kurdyak, P. (2014). Exploring the social determinants of mental health service use using intersectionality theory and CART analysis. Journal Of Epidemiology \& Community Health, 68(2), 145-150. doi:10.1136/jech-2013-203120

[7]. Ziller, E. C., Anderson, N. J., \& Coburn, A. F. (2010). Access to rural mental health services: service use and out-of-pocket costs. The Journal Of Rural Health: Official Journal Of The American Rural Health Association And The National Rural Health Care Association, 26(3), 214-224. doi:10.1111/j.1748-0361.2010.00291.x

[8]. Yoon J, Bernell S. The Role of Adverse Physical Health Events on the Utilization of Mental Health Services. Health Services Research [serial online]. February 2013;48(1):175-194. Available from: Academic Search Complete, Ipswich, MA. Accessed November 8, 2014

[9]. Gould, S., Beals-Erickson, S., \& Roberts, M. (2012). Gaps and Barriers in Services for Children in State Mental Health Plans. Journal Of Child \& Family Studies, 21(5), 767-774. doi:10.1007/s10826-011-9529-1

[10]. Goodwin, R. D., Hoven, C. W., Lyons, J. S., \& Stein, M. B. (2002). Mental health service utilization in the united states. Social Psychiatry and Psychiatric Epidemiology, 37(12), 561-566.

[11]. Enriquez-Haass, V. (2010). Access and utilization of health services among latino immigrant male day laborers in the united states. University of California, Los Angeles). ProQuest Dissertations and Theses, , 158. 863811038?accountid=44936. (863811038).

[12]. Ting, L. (2011). Depressive symptoms in a sample of social work students and reasons preventing students from using mental health services: An exploratory study. Journal of Social Work Education, 47(2), 253-268.

[13]. Christensen, B. N. (2011). Factors affecting mental health service utilization among deployed military personnel. The University of Utah). ProQuest Dissertations and Theses, , 95. Retrieved from accountid=44936. (883360647).

[14]. J. Alonso, M. C. Angermeyer,S. Bernert, R. Bruffaerts,T. S. Brugha, H. Bryson.(2000). Use of mental health services in Europe, ActaPsychiatrScand 2004: 109 (Suppl. 420): 47-54Printed in UK.

[15]. Tamsin Short, Stuart Thomas, Stefan Luebbers, James R. P. Ogloff, Paul Mullen.(2010) Utilization of public mental health servicesin a random community sample. Royal Australian and New Zealand College of Psychiatrists,

[16]. nrique Baca-Garcia $Æ$ Maria M. Perez-Rodriguez $Æ$ Ignacio Basurte-Villamor.(2007) atterns of mental health service utilization in a general hospital and outpatient mental health facilities, Eur Arch Psychiatry ClinNeurosci (2008) 258:117-123.

[17]. Jangho Yoon and Stephanie L. Bernell.(2013) The Role of Adverse PhysicalHealthEvents on the Utilization ofMentalHealth Services, Health Research and Educational TrustDOI: 10.1111/j.1475-6773.2012.01442.xresearch chartl 